\title{
Generalidade da Aprendizagem em Situações de Uso de Ferramentas por um Macaco-Prego, Cebus Apella
}

\author{
Paulo Elias Gotardelo Audebert Delage \\ Olavo de Faria Galvão ${ }^{2}$ \\ Universidade Federal do Pará
}

\begin{abstract}
RESUMO - Estudos sobre o uso de ferramentas em primatas do gênero Cebus divergem sobre se esta habilidade seria do tipo associativa ou "por compreensão". Estudos mostraram que o uso de ferramentas aprendido em um contexto pode se transferir para outros contextos, indicando que algo além da aprendizagem "estímulo-e-resposta" estaria envolvido. Neste estudo um macaco-prego foi exposto a duas situações problema, uma em que o animal precisava encaixar duas varetas para alcançar um pedaço de alimento e outra em que o animal precisava encaixar outro modelo de varetas para golpear um equipamento. Os resultados mostraram que a resolução do primeiro problema facilitou a resolução do segundo, indicando que em novas situações respostas anteriormente bem sucedidas se tornam mais prováveis.
\end{abstract}

Palavras-chave: Cebus apella; compreensão; generalização; uso de ferramentas.

\section{Generality of Learning in Situations Involving Tool Use by a Capuchin Monkey}

\begin{abstract}
Studies with respect to tool use by Cebidae diverge on the question whether this ability is of an associative type, or if an understanding of the function of tools is involved. Studies showed that abilities of tool use learned in one context may transfer to other contexts, indicating that more than "stimulus-response learning" is involved. In this study, a capuchin monkey was exposed to two problem-solving situations, one where two sticks needed to be fit to reach a piece of food and another where the animal needed to fit a different model of sticks to hit an equipment. The results showed that solving the first problem facilitated the solution of the second, indicating that responses which were successful in solving previous problems are more probable to occur in new situations.
\end{abstract}

Keywords: Cebus apella; comprehension; generalization; tool use.

O uso de ferramentas por macacos-prego (Cebus spp.) tem sido amplamente difundido na literatura, com relatos a este respeito em ambiente natural (Fernandes, 1991; Fragaszy, Izar, Visalberghi, Ottoni \& Oliveira, 2004; Ottoni \& Izar, 2008); semi-cativeiro (Ottoni \& Mannu, 2001; Rocha, Reis \& Sekiama, 1998) e em contextos laboratoriais (Anderson \& Henneman, 1994; Bortolini \& Bicca-Marques, 2007; Fragaszy, Visalberghi \& Fedigan, 2004).

Apesar das diversas demonstrações da capacidade desses primatas de usarem ferramentas, existe na literatura uma divergência sobre se tal habilidade seria fruto de uma aprendizagem associativa (Visalberghi \& Limongelli, 1994; Visalberghi, Fragaszy \& Savage-Rumbaugh, 1995) ou se seria fruto da "compreensão" da função da ferramenta (Westergaard \& Fragaszy, 1987; Anderson \& Henneman, 1994; Lavalle, 1999; Visalberghi et al., 2009).

1 Os autores agradecem às agências financiadoras, sem as quais este trabalho não seria possível: à CAPES pela concessão de bolsa de doutorado ao primeiro autor e ao $\mathrm{CNPq}$, pela bolsa de produtividade $1 \mathrm{C}$ concedida ao segundo autor. Agradecemos ainda ao colega Prof. Dr. Thiago Dias Costa pela ajuda na coleta dos dados e elaboração dos equipamentos aqui utilizados. Apoio: CAPES e CNPq

2 Endereço para correspondência: Escola Experimental de Primatas, Laboratório de Psicologia Experimental, IFCH, Universidade Federal do Pará, Campus do Guamá, Belém, PA, Brasil. E-mail: olavo@pq.cnpq. br. Fones: (91) 8186-6933 e 3249-0357.
Os defensores da primeira posição argumentam que a capacidade de usar ferramentas observadas em macacos-prego seria resultante da alta capacidade manipulativa desses animais e de sua curiosidade aguçada, o que os levaria a fortuitamente contatarem situações em que uma determinada ferramenta se mostrasse útil, a partir de quando eles passariam a responder de maneira estereotipada na presença do estímulo "ferramenta".

No outro extremo do debate estão autores, a exemplo dos supracitados, que afirmam que o fato de os animais transportarem ferramentas; escolherem a mais apropriada para uma situação e até mesmo modificá-las antes de usá-las são indícios de que a capacidade desses animais de usar ferramentas vai além da aprendizagem estímulo-resposta e que esses animais demonstram, em determinadas circunstâncias, intencionalidade, caracterizada pela capacidade de compreender o uso que fazem de uma ferramenta e sua função.

Lavalle (1999), por exemplo, argumenta que os resultados encontrados em estudos de laboratório, onde se demonstra um uso estereotipado de ferramentas por macacos-prego, não podem ser usados como evidência de que esses animais não são capazes de compreender o funcionamento das ferramentas, porque esses experimentos são planejados de modo a produzirem um desempenho estereotipado, não envolvendo muita variação entre as respostas necessárias à resolução do problema. 
Uma forma de evitar a ocorrência do problema apontado por este autor é investigar como os animais se valem de habilidades aprendidas em um contexto específico "reaproveitando-as" em contextos mais amplos, por exemplo, utilizando diferentes ferramentas em um mesmo contexto (Generalização; Millenson, 1967/1975); uma mesma ferramenta em diferentes contextos (Generalização Funcional; Epstein, Kirshnit, Lanza \& Rubin, 1984); ou mesmo diferentes ferramentas em diferentes contextos (Learning Set; Harlow, 1947). Em casos em que se observa alguma destas formas de generalização da aprendizagem torna-se mais difícil sustentar que a resolução de um problema se dá por uma associação entre estímulos, uma vez que as situações subseqüentes à de treino são compostas por estímulos diferentes dos presentes na primeira situação (Anderson \& Henneman, 1994; Tokida, Tanaka, Takefushi \& Hagiwara, 1994; Fujita, Kuroshima e Asai, 2003).

Diversos estudos têm demonstrado que a generalidade da aprendizagem para contextos diferentes é um fenômeno comum a diferentes espécies de primatas do velho mundo, como por exemplo Papio cynocephalus anubis (Westergaard, 1992); Macaca Fuscata (Tokida et al., 1994) e Macaque monkeys (Hihara, Obayashi, Tanaka \& Iriki, 2003).

Apesar de não terem sido encontrados experimentos cujo objetivo específico fosse investigar o papel da generalidade da aprendizagem em situações de uso de ferramentas com macacos-prego, tal fenômeno pode ser encontrado em estudos mais gerais sobre uso de ferramentas em macacos desta espécie (Anderson \& Henneman, 1994; Resende \& Ottoni, 2002). Assim, estudos sobre uso de ferramentas têm demonstrado informalmente que a generalidade da aprendizagem é uma característica do uso de ferramentas em macacos-prego.

Considerando-se que o comportamento de usar ferramentas observado em primatas não-humanos provê informações fundamentais para a compreensão da evolução do uso de ferramentas em humanos (Visalberghi et al., 2009), principalmente no que tange as investigações sobre a compreensão que tais animais têm do uso que fazem de tais instrumentos (Visalberghi \& Tomasello, 1998), torna necessário que se realizem maiores investigações sobre o tema em questão.

O presente trabalho teve por objetivo investigar o efeito da generalização da aprendizagem do uso de ferramentas em um Cebus apella cativo, em que habilidades aprendidas em uma situação seriam úteis para a resolução de uma segunda situação, buscando assim uma maior compreensão da forma como esses animais desenvolvem tal habilidade e por extensão aumentando a compreensão do fenômeno da aprendizagem.

\section{Método}

\section{Sujeito}

Como sujeito experimental foi usado um macaco-prego cativo (Cebus apella) com idade aproximada de 4 anos. O sujeito já havia passado por treino de pareamento ao modelo com estímulos visuais apresentados em uma tela sensível ao toque, treino em encaixar varetas, e treino em alcançar pedaços de comida usando uma vareta. Além dessa experiência, ele havia passado ainda por uma sessão de "teste de insight" em que ele deveria combinar duas habilidades (encaixar varetas e usar varetas para alcançar coisas) em uma nova resposta que solucionaria um problema (Carvalho Neto \& Delage, 2006). As sessões de treino em encaixar e alcançar, bem como a de "teste de insight", foram realizadas quando o sujeito tinha uma idade aproximada de um ano. Ou seja, três anos antes do atual experimento.

\section{Equipamento e Material}

Como ambiente experimental foi utilizada a gaiola-viveiro de $15,63 \mathrm{~m}^{3}$, onde o sujeito reside com três outros sujeitos da mesma espécie. Durante as sessões apenas o sujeito experimental ficava livre no interior da gaiola, ficando os outros animais presos em jaulas de isolamento anexas à gaiola-viveiro.

Foi usado um tablado de madeira medindo $1,0 \mathrm{~m}^{2}$, colocado do lado de fora da gaiola viveiro. Sobre esse tablado eram depositadas as varetas (descritas a seguir) e pelotas de alimento a serem alcançadas com as varetas.

Outro equipamento foi construído exclusivamente para este experimento (cf. Fig. 1). Este equipamento era constituído por uma estrutura retangular de metal, com $0,8 \mathrm{~m}$ de altura e $0,5 \mathrm{~m}$ de largura, a cujas paredes laterais foram presos três arames horizontalmente, distando $23,0 \mathrm{~cm}$ entre eles e $11,0 \mathrm{~cm}$ entre o arame superior e a borda da armação. Cada um destes arames traspassa três cuias de aproximadamente $10,0 \mathrm{~cm}$ de diâmetro, distando de 3,0 a 5,0 cm uma da outra e da lateral do equipamento, formando assim uma matriz de $3 \times 3$. Cada uma delas é impedida de correr lateralmente por um pedaço de fita adesiva presa ao arame entre cada uma das cuias, contudo, elas podem girar em torno de seu próprio eixo. Este equipamento recebeu o nome de "cuieiro", em função das cuias que o compõem.

Para o registro dos dados, além da marcação em uma planilha, foi usada uma câmera SONY MiniDV, DCR-HC21.

Foram usados três pares de varetas encaixáveis. Par 1: feito de bambu, era composto de duas partes retas; uma media $27,2 \mathrm{~cm}$ de comprimento e $1,2 \mathrm{~cm}$ de diâmetro e pesava $29 \mathrm{~g}$, a outra media $16,0 \mathrm{~cm}$ de comprimento e $1,6 \mathrm{~cm}$ de diâmetro e pesava $26 \mathrm{~g}$. Quando encaixadas a vareta resultante media $38,0 \mathrm{~cm}$. Par 2: também feito de bambu, tinha uma parte reta e a outra em forma de "T"; a parte reta media $29,0 \mathrm{~cm}$ de comprimento e $1,5 \mathrm{~cm}$ de diâmetro e pesava $34 \mathrm{~g}$. Na parte em "T", a haste principal media $27,5 \mathrm{~cm}$ de comprimento e $1,7 \mathrm{~cm}$ de diâmetro, e o travessão media $21,0 \mathrm{~cm}$ de largura e 1,8 cm de diâmetro; quando encaixadas a vareta resultante passava a medir $48 \mathrm{~cm}$. Par 3: feito em alumínio, era composto de duas partes retas idênticas entre si, e mediam 25,5 $\mathrm{cm}$ de comprimento e $1,0 \mathrm{~cm}$ de diâmetro e pesavam $44 \mathrm{~g}$. Quando encaixadas, as varetas formavam uma haste de 48,7 $\mathrm{cm}$ de comprimento.

Como iscas, ou objetivos, foram usadas pelotas de cereal de chocolate, marca Nescau Ball ${ }^{\circledR}$. 


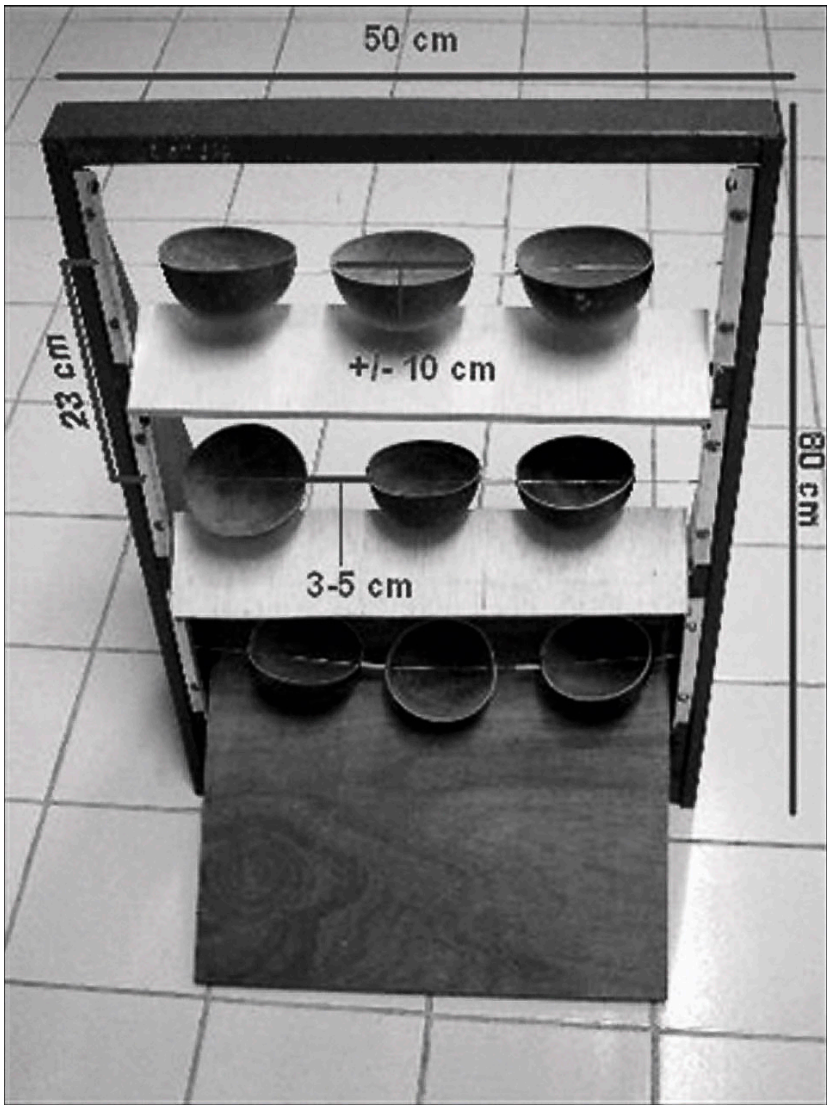

Figura 1. Cuieiro.

\section{Procedimento}

Para o procedimento foram definidas três fases: (1) Linha de Base; (2) Treino de Repertórios Isolados; e (3) Testes.

\section{Fase 1: Linha de Base}

$\mathrm{Na}$ Linha de Base foi apresentado o mesmo problema que veio a ser novamente apresentado ao sujeito na sessão final de teste. Para isto foram depositadas pelotas de Nescau Ball ${ }^{\circledR}$, uma em cada cuia do Cuieiro, que foi posto em frente à gaiola-viveiro a uma distância de $18,0 \mathrm{~cm}$ da mesma, fora do alcance do sujeito. Foram disponibilizadas para o sujeito as duas metades do primeiro par de varetas (retas e de bambu). As varetas enquanto separadas não tinham comprimento suficiente para chegar às cuias, mas se encaixadas formariam uma vareta maior, que poderia ser usada para acertar as cuias, fazendo-as girar em torno de seu eixo, derrubando assim a pelota de comida.

\section{Fase 2: Treino de Repertórios Isolados}

No Treino de Repertórios Isolados o problema foi decomposto em partes mais elementares, a saber, 1. alcançar as cuias usando uma vareta simples, 2. encaixar uma vareta para alcançar uma pelota de alimento sobre o tablado fora da câmara.

\section{Cuieiro}

Para o treino do primeiro repertório o cuieiro foi colocado $9,0 \mathrm{~cm}$ à frente da gaiola e apenas uma das metades da vareta foi disponibilizada para o sujeito, para treinar o sujeito a utilizar essa vareta para acertar as cuias de maneira eficiente e precisa. Os critérios adotados para verificação dos requisitos de eficiência e precisão foram, respectivamente, que o tempo necessário para o recolhimento das nove pelotas deveria ser inferior a 2 min, e que ocorressem um máximo de três tentativas em cuias já esvaziadas. Essa fase foi encerrada quando os critérios foram atingidos em três sessões consecutivas.

\section{Encaixe}

Para o segundo repertório foram disponibilizadas as varetas do Par 2 (em T) sobre o tablado adaptado à parte traseira da gaiola, de modo que para alcançar a pelota de alimento posta em um ponto afastado do tablado o sujeito precisava encaixá-las. Na primeira sessão foram feitas tentativas em que simplesmente se entregava o par de varetas ao sujeito; na segunda sessão foram feitas tentativas com o Par 2 encaixado $(48,0 \mathrm{~cm})$, alternadas com tentativas com a metade superior apenas (também em T, mas com 27,5 cm), sendo que na primeira condição a pelota ficava a $50,0 \mathrm{~cm}$ da gaiola e na segunda a $25,0 \mathrm{~cm}$. Após duas tentativas de cada condição passou-se a fazer tentativas em que a pelota era colocada a $50,0 \mathrm{~cm}$ da grade da gaiola e as duas metades da vareta eram inicialmente entregues desmontadas e após o sujeito tê-las manipulado sem resultado favorável, elas eram encaixadas na frente dele e depois disponibilizadas montadas, podendo assim ser usada para alcançar a pelota. A fim de aumentar a probabilidade de que o sujeito encaixasse as metades da vareta, elas passaram a ser apresentadas com as pontas de encaixe bem próximas uma da outra, quase que encaixadas. Posteriormente as metades passaram a ser disponibilizadas cada vez mais distantes uma da outra.

O objetivo desta etapa era treinar o sujeito a encaixar a vareta rápida e firmemente. A cada tentativa correta a vareta era recolhida, desmontada e somente então disponibilizada novamente. $\mathrm{O}$ critério para encerrar esta fase era de que o sujeito deveria, por 3 sessões consecutivas, encaixar as metades da vareta e usá-la nove vezes em um tempo máximo de $135 \mathrm{~s}$ (média de $15 \mathrm{~s}$ para cada tentativa).

Assim, foram realizados treinos explícitos em cada um dos repertórios, com o sujeito passando por um treinamento em usar uma vareta para bater nas cuias e virá-las para obter a pelota nela contida, e em encaixar as varetas para alcançar e puxar a comida no tablado. Cada uma dessas sessões era realizada de forma alternada, de modo que em um dia o repertório treinado era o de alcançar as cuias, e no dia seguinte era feito o treino de encaixar para alcançar as pelotas no tablado. $\mathrm{O}$ procedimento de treino adotado nesta fase para cada um dos repertórios foi sendo construído a partir dos resultados do sujeito ao longo das sessões.

\section{Fase 3: Testes}

Depois de ter passado pelos treinos em cada um dos repertórios separados o sujeito foi novamente exposto à situação 
problema, com o cuieiro fora de seu alcance direto e com duas metades de uma vareta que, se encaixadas, poderiam ser usadas para alcançar as cuias cheias de comida.

Foram feitos três testes. O primeiro foi idêntico ao pré-teste, com o cuieiro a 18,0 cm da frente da gaiola e o Par 1 (varetas retas de bambu) disponível para o sujeito.

O segundo teste foi similar ao primeiro, com a diferença de que desta feita foi usado o Par 3 (varetas retas de alumínio) e o cuieiro foi colocado a $20,0 \mathrm{~cm}$ da frente da gaiola em função da adaptação da distância ao comprimento da nova vareta.

Um terceiro teste idêntico ao anterior foi feito 20 dias depois desse. O objetivo desse teste era avaliar se mesmo após este período e sem nenhum treino adicional em nenhum dos componentes da tarefa o sujeito ainda poderia resolver o problema. Além disso, após a realização da primeira tentativa, foram feitas pequenas variações no problema a cada nova apresentação do mesmo. Na primeira variação uma vareta foi posta na lateral da gaiola, a cerca de 2,0 $\mathrm{m}$ do equipamento e da outra vareta; na segunda variação, uma das varetas foi posta do outro lado da gaiola, a cerca de 3,0 $\mathrm{m}$ do equipamento e da outra vareta; e por fim, em outra variação, uma vareta foi colocada fora do alcance do sujeito do lado de fora da gaiola, de modo que ele precisasse usar a outra vareta para alcançar a aquela e assim poder montá-las e usá-las apropriadamente.

A Tabela 1 apresenta um resumo dos procedimentos e objetivos de cada uma das etapas do procedimento.

\section{Resultados}

\section{Fase 1: Linha de Base}

Quando o teste foi apresentado pela primeira vez na sessão de Linha de Base o sujeito não foi capaz de resolvê-lo, tendo apresentado respostas de morder, bater, jogar e carregar direcionadas às metades da vareta. Por 12 vezes ele segurou a metade fina da vareta (ligeiramente maior que a outra metade) e movimentou-a em direção ao cuieiro, tendo passado $102 \mathrm{seg}$ executando essa atividade. A resposta de jogar a vareta em direção do cuieiro ocorreu 12 vezes, sendo seis vezes com cada uma delas.

Foram registradas 11 respostas de manipulação das varetas, sendo sete delas realizadas com as duas metades

Tabela 1. Apresentação resumida das fases do procedimento

\begin{tabular}{|c|c|c|}
\hline Fase & Procedimento & Objetivo \\
\hline Linha de Base & Apresentação Inicial do Problema & $\begin{array}{l}\text { Verificar se o sujeito era capaz de resolver o } \\
\text { problema antes que qualquer intervenção fosse } \\
\text { feita }\end{array}$ \\
\hline $\begin{array}{l}\text { Treino de Repertórios } \\
\text { Isolados: Cuieiro }\end{array}$ & $\begin{array}{l}\text { O sujeito deveria usar uma vareta simples } \\
\text { para alcançar as pelotas no Cuieiro }\end{array}$ & $\begin{array}{l}\text { Garantir que o sujeito fosse capaz de recolher as } \\
\text { pelotas na hora do teste. }\end{array}$ \\
\hline $\begin{array}{l}\text { Treino de Repertórios } \\
\text { Isolados: Encaixe }\end{array}$ & $\begin{array}{l}\text { O sujeito foi treinado a encaixar duas } \\
\text { varetas de bambu, uma delas em formato } \\
\text { de "T" para alcançar uma pelota }\end{array}$ & $\begin{array}{l}\text { Garantir um histórico de encaixe de um modelo } \\
\text { de vareta diferente do usado no teste } \\
\text { Treiná-lo a encaixar para realizar uma ação } \\
\text { distinta (alcançar) da realizada no teste (golpear) }\end{array}$ \\
\hline Teste 1 & $\begin{array}{l}\text { Expor o sujeito à mesma situação } \\
\text { problema apresentada na Linha de Base }\end{array}$ & $\begin{array}{l}\text { Verificar se após o treino nos dois repertórios } \\
\text { isolados o sujeito seria capaz de resolver o } \\
\text { problema que originalmente não fora capaz }\end{array}$ \\
\hline Teste 2 & $\begin{array}{l}\text { Expor o sujeito a uma situação problema } \\
\text { similar à apresentada na Linha de Base, } \\
\text { usando varetas diferentes }\end{array}$ & $\begin{array}{l}\text { Verificar se após o treino nos dois repertórios } \\
\text { isolados o sujeito seria capaz de resolver } \\
\text { problemas usando ferramentas inéditas }\end{array}$ \\
\hline Testes 3 & $\begin{array}{l}\text { Expor o sujeito a variações mais } \\
\text { complexas do problema apresentado na } \\
\text { Linha de Base }\end{array}$ & $\begin{array}{l}\text { Verificar se após a história de resolução de } \\
\text { problemas o sujeito seria capaz de resolver } \\
\text { problemas mais complexos para os quais ele } \\
\text { nunca havia sido treinado }\end{array}$ \\
\hline
\end{tabular}


concomitantemente, tendo passado $61 \mathrm{seg}$ realizando essa atividade. Em duas ocasiões (aos 11:12 min e aos 17:02 min) o sujeito chegou a posicionar as metades da vareta para encaixe, sem completar o encaixe.

\section{Fase 2: Treino de Repertórios Isolados}

Como o sujeito não foi capaz de resolver o problema, tiveram início as sessões de treino em Repertórios Isolados.

\section{Cuieiro}

Assim que a primeira sessão com o cuieiro teve início o sujeito imediatamente (0:03 seg) utilizou a vareta para alcançar a cuia. Foram necessários 4:42 min para que o sujeito virasse todas as cuias e recolhesse todas as pelotas, tendo virado cuias vazias 10 vezes.

Como na primeira sessão o sujeito foi bem sucedido em alcançar as cuias, o procedimento foi mantido para as demais sete sessões de treino ao cuieiro até que os critérios de tempo e acertos fossem atingidos.

\section{Encaixe}

Já com relação ao repertório de encaixe, na primeira sessão de treino deste repertório o sujeito não foi capaz de encaixar espontaneamente as duas varetas mesmo depois de decorridos os 10 min previstos para a sessão.

Como o sujeito não se mostrou hábil em realizar a tarefa conforme apresentada anteriormente, foi realizada uma sessão de treino gradual de encaixar as varetas antes que a situação problema fosse novamente apresentada. O sujeito foi inicialmente exposto a uma situação em que ele podia pegar o alimento no tablado com uma vareta curta (metade em T), em seguida foi apresentada uma situação em que as varetas eram entregues encaixadas ao sujeito, e ele precisava usá-las assim para alcançar a pelota. Foram alternadas três tentativas com uma metade da vareta (curta) e três com as varetas encaixadas, sendo que nestas tentativas as varetas eram encaixadas na presença do sujeito, sempre garantindo que ele estivesse com os olhos voltados para a vareta naquele instante.

Após as 6 tentativas iniciais, três com uma metade da vareta e três com as metades encaixadas, o alimento foi posto no ponto mais afastado do tablado, de modo que o sujeito agora precisava da vareta longa para chegar até ele. No entanto, agora a vareta foi entregue desmontada para o sujeito. Como após 4 min o sujeito ainda não havia resolvido o problema, o experimentador apresentou uma situação facilitada para o sujeito, com as varetas sendo colocadas de forma contígua, quase encaixadas. Com este novo arranjo o sujeito rapidamente ( $2 \mathrm{seg}$ ) resolveu o problema, encaixando-as. A partir deste instante foram feitas mais três tentativas facilitadas, às quais o sujeito prontamente respondeu apropriadamente.

Depois disso foram feitas mais seis tentativas com as varetas sendo entregues progressivamente mais separadas a cada tentativa. Em todas as ocasiões o sujeito prontamente encaixava as duas metades e usava a ferramenta adequadamente para alcançar o objetivo.

Após essas seis tentativas facilitadas foram feitas cinco tentativas em que as varetas eram entregues separadamente. Desde a primeira tentativa desse tipo o sujeito já apresentou respostas de encaixar a vareta, inclusive reencaixando-as quando necessário. Foi necessária apenas uma sessão deste procedimento de modelagem.

Foram necessárias seis sessões de fortalecimento para que o sujeito atingisse o critério previsto de desempenho nas habilidades de encaixar e usar as varetas encaixadas para alcançar o objetivo.

\section{Fase 3: Testes}

\section{Teste 1}

Atingidos os critérios de desempenho previstos para os dois repertórios, foi realizada a primeira sessão de teste, quando o sujeito não foi capaz de resolver o problema pois ele destruiu a parte grossa da vara de bambu, tendo sido a sessão encerrada aos 6 min e 50 seg em função deste incidente.

Por 12 vezes o sujeito tentou alcançar o cuieiro com uma das metades da vareta, sendo 10 tentativas com a parte fina e duas com a parte grossa. O tempo total despendido com essa classe de respostas foi de $39 \mathrm{seg}$. Outra resposta relevante foi a de jogar as varetas em direção ao cuieiro. Foram registradas 18 respostas pertencentes a esta classe, sendo 16 dessas respostas emitidas com parte fina e duas com a parte grossa.

Não foram registradas quaisquer respostas de manipular as varetas, quer separadas ou em conjunto.

\section{Teste 2}

Como o primeiro teste precisou ser interrompido prematuramente em função da destruição da vareta pelo sujeito, foram feitas novas varetas, desta vez em alumínio e um novo teste foi realizado. No teste o sujeito resolveu o problema, tendo encaixado as varetas de alumínio aos 2 min e $40 \mathrm{seg}$, usando-a 9 seg depois ( 2 min e $49 \mathrm{seg}$ ) para alcançar uma das cuias do cueiro.

Nessa sessão as duas metades foram entregues ao mesmo tempo, sendo uma depositada à direita do cuieiro e a outra à esquerda. Aos $3 \mathrm{seg}$ o sujeito pegou uma das partes da vareta, largando-a em seguida aos $9 \mathrm{seg}$, voltando a pegá-la aos 1 min e $35 \mathrm{seg}$. Nesta ocasião o sujeito olhou o furo na parte inferior da vareta pela primeira vez. Tentou alcançar o cuieiro aos $1 \mathrm{~min}$ e $41 \mathrm{seg}$ com uma vareta, jogou-a em seguida, aos $1 \mathrm{~min}$ e $43 \mathrm{seg}$. Aos $1 \mathrm{~min}$ e $48 \mathrm{seg}$ pegou novamente a vareta e tentou alcançar o cuieiro ( 1 min e 51 seg), levando-a em seguida (1 min e $57 \mathrm{seg}$ ) para o fundo da gaiola, onde a usou para alcançar uma migalha de comida que estava ali desde antes do início da sessão (2 $\min$ ). Aos 2 min e $11 \mathrm{seg}$ o sujeito retornou para próximo do equipamento com a metade da vareta na mão, pegou a outra metade ( 2 min e $29 \mathrm{seg}$ ) e encaixou as duas aos 2 min e $43 \mathrm{seg}$, tendo usado a vareta para alcançar a pelota de 


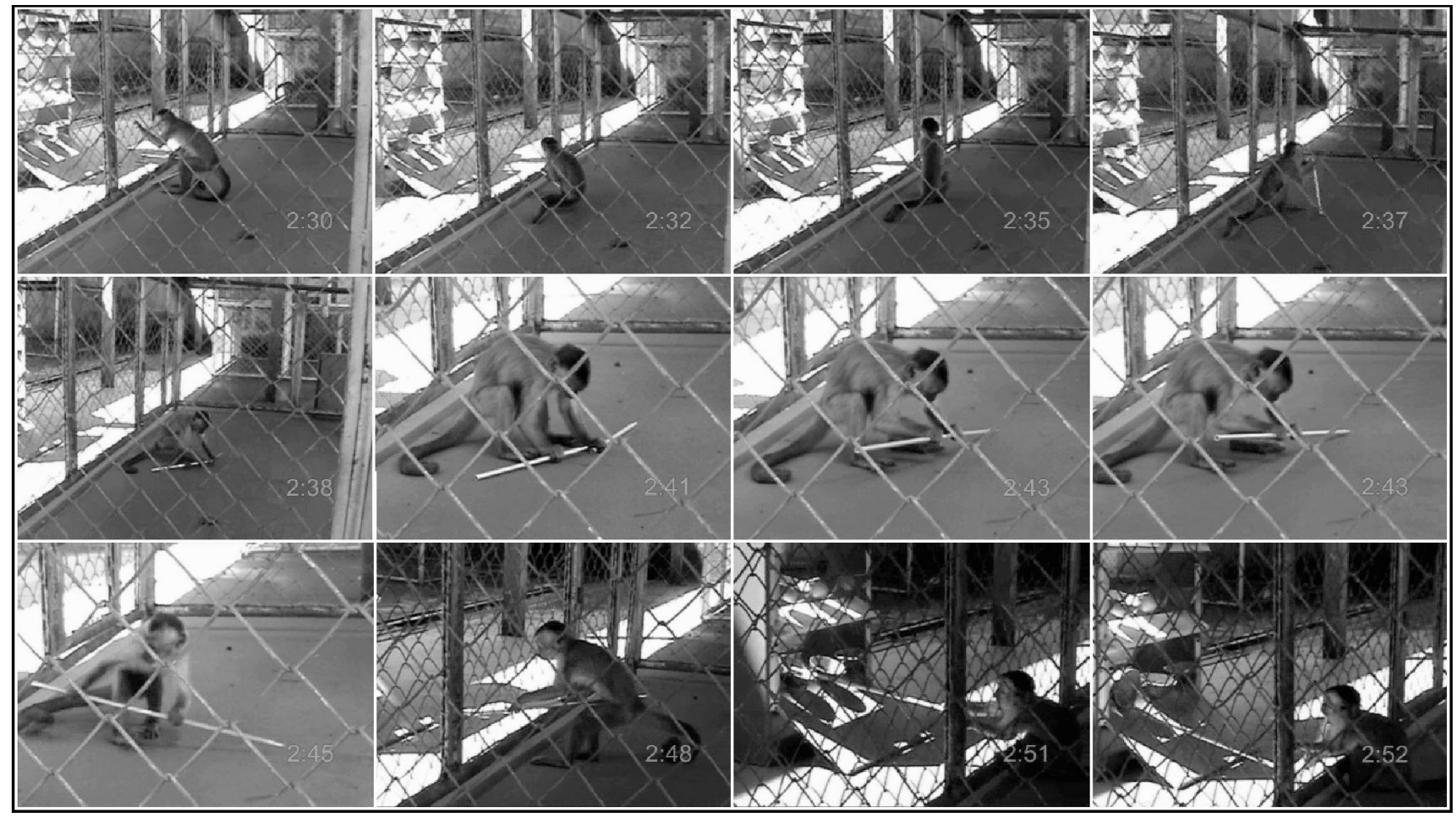

Figura 2. Seqüência de fotografias que retratam a resolução do problema durante o segundo teste de encaixe de varetas pelo sujeito.

alimento pela primeira vez aos 2 min e 51 seg (ver Figura 1). O sujeito voltou a usar a vareta completa, sem deixar que ela desencaixasse, por mais duas vezes: uma aos $3 \mathrm{~min}$ e outra aos 3 min e 11 seg.

\section{Teste 3.1}

A fim de verificar a manutenção do repertório aprendido, uma nova sessão de teste, idêntica à anterior, foi executada 20 dias após a anterior.

Nesta sessão as varetas foram entregues ao mesmo tempo, exatamente como feito na sessão anterior, e o sujeito pegou a primeira metade aos 6 seg e tentou usá-la aos $11 \mathrm{seg}$. Aos 17 seg pegou a outra metade da vareta e encaixou as duas aos $20 \mathrm{seg}$, tendo-as desencaixado em seguida $(21 \mathrm{seg})$. Aos 26 seg ele as encaixou novamente, mas ao movê-las elas se desencaixaram (28 seg), tendo o sujeito voltado a manipulá-las em seguida. As manipulações seguiram até os $42 \mathrm{seg}$, quando o sujeito novamente as encaixou, tendo usado a vareta completa para alcançar duas cuias com alimento em seguida (uma aos $47 \mathrm{seg}$ e outra aos $55 \mathrm{seg}$ ).

\section{Teste 3.2}

Depois do sujeito ter usado a vareta por duas vezes, a mesma foi recolhida pelo experimentador, desencaixada e suas partes reapresentadas ao sujeito, tendo início uma nova tentativa. Desta vez uma metade foi posta ao lado do cuieiro e a outra na lateral da gaiola (a cerca de 2,0 $\mathrm{m}$ do equipamento). Com essa configuração o sujeito pegou a vareta que estava mais afastada aos $8 \mathrm{seg}$, levando-a em seguida para próximo do equipamento, onde pegou a outra vareta (12 seg) e as encaixou novamente aos $29 \mathrm{seg}$, tendo usado a vareta montada para alcançar uma cuia com alimento aos $32 \mathrm{seg}$, uma aos $46 \mathrm{seg}$ e outra aos $58 \mathrm{seg}$, tendo as varetas sido recolhidas em seguida.

\section{Teste 3.3}

Recolhidas as varetas, as mesmas foram novamente desencaixadas e reapresentadas em seguida, sendo uma delas deixada próximo ao equipamento e a outra no fundo da gaiola (a aproximadamente 3,0 $\mathrm{m}$ de distância do equipamento). Aos $17 \mathrm{seg}$ o sujeito pegou a vareta mais distante e se aproximou do equipamento, tendo pegado a outra vareta aos $26 \mathrm{seg}$ e as encaixado aos $35 \mathrm{seg}$, quando então ela foi usada para alcançar o conteúdo de outras duas cuias (uma aos 46 seg e outra aos $54 \mathrm{seg})$.

\section{Teste 3.4}

Para a última tentativa uma vareta foi deixada próxima do equipamento e a outra foi deixada fora do alcance direto do sujeito, de modo que ele precisasse usar a vareta ao seu alcance para ter acesso à outra e, só então, poder encaixá-las e assim chegar ao objetivo. Aos 5 seg o sujeito pegou a metade da vareta ao seu alcance e passou a usá-la para tentar chegar à metade mais afastada, tendo feito isso até os $22 \mathrm{seg}$, quando ele conseguiu ter acesso à segunda metade. Em seguida, aos $31 \mathrm{seg}$, o sujeito encaixou as duas metades e aos 40 seg usou a vareta inteira para atingir uma cuia. 


\section{Discussão}

Os resultados encontrados tornam difícil sustentar que o sujeito tivesse uma compreensão no sentido estrito do termo, uma vez que caso o controle do comportamento de usar a ferramenta fosse fruto de uma racionalização por parte do sujeito seria esperado que ele tivesse resolvido o problema já na primeira vez que o mesmo lhe foi apresentado, uma vez que ele já "sabia" o que fazer em situações deste tipo (o sujeito tinha treino prévio no uso de ferramentas), e não apenas após uma série de sessões de treino em repertórios componente da cadeia final.

Contudo, afirmar que o uso de ferramentas pelo sujeito durante o teste foi uma aprendizagem fortuita do tipo tentativa-e-erro é ignorar o processo de resolução do problema, uma vez que quando o sujeito foi exposto ao problema depois de passar pelos treinos nos repertórios componentes da tarefa ele não iniciou uma série de tentativas arbitrárias como na primeira vez quem que foi exposto ao problema. Além disto, o sujeito prontamente utilizou a vareta depois tê-la encaixado, não tendo contatado sua nova funcionalidade apenas após várias tentativas ao acaso, indicando que a aprendizagem da relação tamanho/alcance aprendida no contexto de treino foi generalizada para a situação problema.

Outro ponto importante em defesa de uma resolução do tipo "por compreensão" está o fato de que o sujeito foi capaz de resolver variações do problema sem que novos treinos fossem necessários (Testes 3.2, 3.3 e 3.4), sendo que o problema resolvido no Teste 3.4 apresenta um maior número de ordens, e portanto mais complexo que os anteriores, segundo classificação adotada por Fragaszy, Visalberghi e Fedigan (2004).

É importante frisar que quando é dito que o sujeito passou por sessões de treino nos repertórios componentes da resposta final, mas que isto não se constituiu em um treino direto ao problema, justifica-se tal afirmação com base nas diferenças observadas nas duas condições, com as duas situações diferindo com relação a uma ampla gama de fatores, como por exemplo: diferenças quanto a forma, espessura e material das varetas; a resposta final exigida, a saber, puxar uma pelota e bater em um objeto; os equipamentos utilizados e suas posições relativas (para maiores detalhes sobre a importância da disposição dos equipamentos em situações de resolução de problemas, ver Dubois, Gerard, Sampaio, Galvão, \& Guilhem, 2001).

Assim, o que se pode concluir a partir dos resultados aqui encontrados é que a chamada "compreensão" do uso da ferramenta por Cebus apella pode ser entendida não como um processo de ordem mental e reflexivo, mas sim como um "Operante de Segunda Ordem" (Catania, 1999); um comportamento complexo que vai sendo construído a partir de múltiplas exposições a diferentes situações, mas que guardam propriedades funcionais similares, gerando assim um efeito de "Learning Set" (Harlow, 1947).

Em suma, afirmar que o uso de ferramentas por Cebus apella é controlado unicamente pela disposição dos estímulos presentes na situação-problema parece ser super-simplificar o fenômeno; ao mesmo tempo dizer que essa capacidade é fruto de conjecturas e racionalizações não parece descrever o processo em sua completude.
O mais provável é que dependendo do procedimento adotado e histórico dos sujeitos os resultados possam ser mais próximos de uma ou outra abordagem. Assim, é compreensível que em estudos como os de Lavalle (1999) ou Anderson e Henneman (1994), em que os animais são expostos a diferentes ferramentas, objetivos e contextos experimentais, os animais tenham um padrão mais próximo do que se convencionou chamar de "racional"; em contrapartida, em estudos como dos de Visalberghi e Limongelli (1994), em que os animais são expostos a exaustivas repetições de um mesmo tipo de problema, é justificável que os animais apresentem padrões mais estereotipados de ação.

$\mathrm{O}$ estudo aqui apresentado foi o primeiro de uma série que pretende investigar o efeito de transferência de aprendizagem e formação de Learning Sets em situações de uso de ferramentas em Cebus apella. A investigação de novos problemas em que são manipuladas as diferenças funcionais entre cada problema permitirá estabelecer com maior precisão as variáveis que afetam o grau de generalidade da aprendizagem para diferentes contextos nos macacos-prego.

\section{Referências}

Anderson, J. R., \& Henneman, M. C. (1994). Solutions to a tool-use problem in a pair of Cebus apella. Mammalia, 58, 351-361.

Bortolini, T. S., \& Bicca-Marques, J. C. (2007). A case of spontaneous tool-making by a captive capuchin monkey. Neotropical Primates, 14, 74-76.

Carvalho Neto, M. B., \& Delage, P. E. G. A. (2006). Criatividade e Análise do Comportamento. Curso ministrado no XV Encontro Brasileiro de Psicoterapia e Medicina Comportamental, Brasília, Brasil

Catania, A. C., (1999). Aprendizagem: Comportamento, Linguagem e Cognição. (D.G. Souza, Trad.) Porto Alegre: Artmed. (Trabalho original publicado em 1984)

Dubois, M., Gerard, J. F., Sampaio, E., Galvão, O. F., \& Guilhem, C. (2001). Spatial facilitation in a probing task in wedgecapped capuchins (Cebus Olivaceus). International Journal of Primatology, 22, 993-1006.

Epstein, R., Kirshnit, C., Lanza, R., \& Rubin, L. (1984). „Insight“ in the pigeon: antecedents and determinants of an intelligent performance. Nature, 308, 61-62.

Fernandes, E. B. M. (1991). Tool use and predation of oysters by the tufted capuchin in brackish water mangrove swamp. Primates, 32, 529-531.

Fragaszy, D. M., Visalberghi E., \& Fedigan, L. M. (2004). The complete capuchin: the biology of the genus Cebus. Cambridge: Cambridge University Press.

Fragaszy, D. M., Izar, P., Visalberghi, E., Ottoni, E. B., \& Oliveira, M. G. (2004). Wild capuchin monkeys (Cebus libidinosus) use anvils and stone pounding tools. American Journal of Primatology, 64, 359-366.

Fujita, K., Kuroshima, H., \& Asai, S. (2003). How do tufted capuchin monkey (Cebus apella) understand causality involved in tool use? Journal of Experimental Psychology: Animal Behavior Process, 29, 233-242.

Harlow, H. F. (1947). The formation of learning sets. Psychological Review, 56, 51-65. 
Hihara, S., Obayashi, S., Tanaka, M., \& Iriki, A. (2003). Rapid learning of sequential tool use by macaque monkeys. Physiology \& Behavior, 78, 427-434.

Lavalle A. C. (1999). Capuchin tool use in a captive naturalistic environment. International Journal of Primatology, 20, 399414.

Millenson, J. R. (1975). Princípios de análise do comportamento (A. A. Souza \& D. Rezende, Trad.). Brasília: Coordenada (Trabalho original publicado em 1967).

Ottoni, E. B., \& Mannu, M. (2001). Semifree-ranging tufted capuchins (Cebus apella) spontaneously use tools to crack open nuts. International Journal of Primatology, 22, 347-358.

Ottoni, E. B., \& Izar, P. (2008). Capuchin monkey tool use: overview and implications. Evolutionary Anthropology, 17, 171-178.

Resende, B. D., \& Ottoni, E. B. (2002). Brincadeira e aprendizagem do uso de ferramentas em macacos-prego (Cebus apella). Estudos de Psicologia, 7, 173-180.

Rocha, J. V., dos Reis, N. R., \& Sekiama, M. L. (1998). Uso de ferramentas por Cebus apella para obtenção de larvas de Coleóptera que parasitam sementes de S. romanzofianum. Revista Brasileira de Zoologia, 15, 945-950.

Tokida, E., Tanaka, I., Takefushi H., \& Hagiwara T. (1994). Tooluse in Japanese Macaques: use of stones to obtain fruit from a pipe. Animal Behavior, 47, 1023-1030.

Visalberghi, E., Fragaszy, D. M., \& Savage-Rumbaugh, S. (1995). Performance in a tool-using task by common chimpanzees (Pan troglodytes), bonobos (Pan paniscus), orangutan (Pongo pygmaeus) and capuchin monkeys (Cebus apella). Journal of Comparative Psychology, 109, 52-60.
Visalberghi, E., \& Limongelli, L. (1994). Lack of comprehension of cause-effect relations in tool-using capuchin monkeys (Cebus apella). Journal of Comparative Psychology, 108, 15-22.

Visalberghi, E., Spagnoletti, N., Silva, E. D. R., Andrade, F. R. D., Ottoni, E., Izar, P., \& Fragaszy, D. (2009). Distribution of potential suitable hammers and transport of hammer tools and nuts by wild capuchin monkeys. Primates, 50, 95-104.

Visalberghi, E., \& Tomasello, M. (1998). Primate causal understanding in the physical and psychological domains. Behavioral Processes, 42, 189-203.

Westergaard, G. C. (1992). Object Manipulation and the Use of Tools by Infant Baboons (Papio cynocephalus anubis). Journal of Comparative Psychology, 106, 398-403.

Westergaard, G. C., \& Fragaszy, D. M. (1987). The manufacture and use of tools by capuchin monkeys. Journal of Comparative Psychology, 101, 159-168. 